\title{
Transitioning to Transradial Access for Cerebral Aneurysm Embolization
}

\author{
(D). Chivot, DR. Bouzerar, and (D)T. Yzet
}

\begin{abstract}
BACKGROUND AND PURPOSE: Despite several retrospective studies showing the safety and efficacy of transradial access for cerebral angiography, neurointerventionalists are apprehensive about implementing TRA for neurointerventions. This reluctance is mainly due to anatomic factors, technical factors, and a long learning curve (relative to transfemoral access). We present here our experience of TRA transition for cerebral aneurysm embolization. Our aim was to demonstrate the feasibility and safety of radial access for consecutive embolizations of ruptured and unruptured cerebral aneurysms.
\end{abstract}

MATERIALS AND METHODS: We performed a retrospective review of a prospective data base on cerebral aneurysm embolizations. Between April and December 2018, radial access was considered for all consecutive patients referred to our institution for cerebral aneurysm embolization. Technical success was defined as radial access with insertion of the sheath and completion of the intervention without a crossover to conventional femoral access. The primary safety end point was the in-hospital plus 30-day incidence of radial artery occlusion. Secondary end points included intraoperative complications and neurologic complications at discharge and in the following 30 days.

RESULTS: Seventy-one patients with a cerebral aneurysm underwent 73 embolization procedures at our institution. The first-choice access route was the radial artery in 62 patients (87.3\%) and the femoral artery in 9 (12.6\%). Thirty-four embolizations were performed using coils, 22 used a balloon-assisted coil technique, 6 used a stent-assisted coil technique, and 2 used a flow diverter. Crossover to femoral access was observed in 2 patients (3.1\%). Four patients developed coil-induced thrombi requiring intra-arterial tirofiban injections. In 1 case, an aneurysm ruptured during the operation but did not have a clinical impact. No cases of radial artery occlusion or hand ischemia were observed.

CONCLUSIONS: A transition to radial access for cerebral aneurysm embolization is feasible and does not increase the level of risk associated with the procedure.

ABBREVIATIONS: POD = postoperative day; TFA = transfemoral access; TRA = transradial access

T ransradial access (TRA) for transcatheter coronarography has been performed for $>25$ years, and several studies have found that it is safer than transfemoral access (TFA). ${ }^{1-8}$ The European Society of Cardiology recommends TRA as the firstline approach for coronary diagnosis and therapy because this method is associated with a lower hemorrhage risk, a shorter length of hospital stay, a shorter period of immobilization, lower costs, and greater levels of patient satisfaction. ${ }^{9}$ Despite these clear benefits, TRA is underused in neuroradiology; surgeons

Received June 20, 2019; accepted after revision August 13.

From the Departments of Radiology (C.C., T.Y.) and Image Processing (R.B.), Amiens University Hospital, Amiens, France.

Please address correspondence to Cyril Chivot, MD, Department of Radiology, Hôpital Sud, Centre Hospitalier Universitaire d'Amiens, Ave René Laennec, F-80054, Amiens Cedex 01, France; e-mail: chivot.cyril@chu-amiens.fr

http://dx.doi.org/10.3174/ajnr.A6234

tend to reserve it for posterior fossa aneurysm embolization or after TFA has failed. This reluctance is mainly due to anatomic factors, technical factors, and a long learning curve (relative to TFA). A small radial artery diameter is an anatomic factor of major concern, puncture is considered more difficult than in TFA, and a small diameter prevents the use of large catheters required for interventions (eg, flow diverters). With regard to technical factors, the lack of dedicated equipment for TRA is a major issue because the catheter transition zones are adjusted for TFA; therefore, stability may be a problem during TRA. The literature data show that in cardiology, a 50-case learning curve is required to decrease the complications and crossover rates. ${ }^{10}$

It is likely that the learning curve in neuroradiology would be the same, though the number of patients treated is obviously lower than in cardiology. Consequently, the longer time needed to gain sufficient experience might explain the surgeons'

AJNR Am J Neuroradiol 40:1947-53 Nov 2019 www.ajnr.org 
reluctance to use TRA. Nevertheless, TRA has true value in neuroradiology because a growing proportion of stent placements require dual-antiplatelet therapy, increasing the risk of hemorrhagic complications at the puncture site. The proportion of patients with obesity is also increasing, and TRA is easier and safer than TFA in this population. ${ }^{11}$ Last, the most important benefit of using TRA is greater comfort for the patient.

In view of the many reported advantages of TRA (notably with regard to feasibility and safety in diagnostic cerebral angiography ${ }^{12,13}$ ), our institution began transitioning all its diagnostic cerebral angiography examinations to TRA. Next, after a few months of practice, we decided to use TRA for all cerebral embolization procedures. Two recent cohort studies ${ }^{12,13}$ found that TRA was safe for the embolization of unruptured cerebral aneurysms, though the patients were probably selected and not consecutive. The objective of the present study was thus to determine the feasibility and safety of a transition to TRA for consecutive embolizations of ruptured or unruptured cerebral aneurysms.

\section{MATERIALS AND METHODS}

We reviewed our prospective data base on cerebral aneurysm embolizations performed between April and December 2018. During this period, TRA was considered for all consecutive patients addressed for cerebral aneurysm embolization at our institution. This retrospective, single-center study was approved by the institutional review board. The board waived the need for informed consent.

\section{The Endovascular Procedure}

All embolizations were performed with the patient under general anesthesia by the same surgeon (C.C.) with 5 years of experience in TFA cerebral embolization. Before puncture, a Barbeau test was performed to check the patency of the superficial palmar arch. Radial access was suitable only for patients with Barbeau AC waveforms.

The patient's arm was positioned on a swivel-arm board at his or her side. Access to the radial artery was obtained using an anterior or counter-puncture technique at the start of our series and using sonographic guidance for the last 20 patients. Once the $6 \mathrm{~F}$ radial sheath had been placed, we injected a medication cocktail ( $2.5 \mathrm{mg}$ of verapamil and $250 \mu \mathrm{g}$ of nitroglycerine) directly through it. Intravenous heparin $(50 \mathrm{U} / \mathrm{kg})$ was administered to maintain an activated clotting time between 250 and 350 seconds.

A $6 \mathrm{~F}$ sheath was placed in the right (preferably) radial artery, and supra-aortic vessels were catheterized by advancing a $6 \mathrm{~F}$ Envoy catheter (Codman \& Shurtleff, Raynham, Massachusetts) or a Benchmark catheter (Penumbra, Almeda, California) over a 130-cm 5F Simmons 2-shaped catheter (Penumbra for anterior circulation, or over a $125-\mathrm{cm} 5 \mathrm{~F}$ Berenstein diagnostic catheter [Penumbra]) for the posterior circulation, as described previously by Snelling et al. ${ }^{14}$

For flow-diverter placement (Pipeline Flex; Covidien, Irvine, California), a 0.088-inch-internal-diameter guide catheter was inserted sheathlessly with an intermediate catheter (Sofia; MicroVention, Tustin, California) after ensuring that the diameter of the radial artery was $>2.5 \mathrm{~mm}$. When the diameter was $<2.5 \mathrm{~mm}$, TFA was preferred.
For remodeling techniques, a dual-lumen balloon catheter (Scepter C or XC; MicroVention) and a microcatheter (Excelsior SL 10; Stryker, Kalamazoo, Michigan) were placed in the same guide catheter (Envoy; DePuy Synthes, Warsaw, Indiana; or Benchmark), and coils were deployed through the microcatheter using standard techniques.

Stents (Neuroform Atlas, Stryker; or LEO Baby stent, Balt Extrusion, Montmorency, France) were placed through the microcatheter (Excelsior SL 10) using standard techniques.

\section{Outcome}

Technical success was defined as TRA with insertion of the sheath and completion of the cerebral aneurysm procedure without crossover to conventional TFA.

The safety end point was the in-hospital plus 30-day incidence of radial artery occlusion. This was evaluated 24 hours after the procedure, at discharge, and on postoperative day (POD) 30. The secondary end points included the in-hospital incidence of access site hematoma, pseudoaneurysm, arteriovenous fistula, infection, or neurologic complications requiring an operation, together with a composite of these. At each follow-up visit, the access site was inspected. The secondary end points also included cerebral thromboembolic and hemorrhagic complications and vessel injury. Patients underwent a physical examination by a neurologist 24 hours after the procedure, at discharge, and on POD 30.

\section{RESULTS}

Between April and December 2018, seventy-one patients with cerebral aneurysms underwent 73 embolization procedures (all performed by the same operator) at our institution. The firstchoice access route was the radial artery in 62 patients $(87.3 \%)$ and the femoral artery in $9(12.6 \%)$. The study populations' baseline clinical and radiologic characteristics are summarized in Table 1 . In the subset of 62 patients treated with TRA, 33 were treated on an emergency basis for a ruptured aneurysm, and 29 underwent scheduled embolization for an unruptured aneurysm. Two patients had a second embolization after recanalization: One procedure was performed with coils, and the other, with flow diverters.

\section{Intervention Site}

Of the 64 embolization procedures with TRA performed in the 62 cases, 56 and 8 (87.5\% and 12.5\%) involved the anterior and posterior circulations, respectively. The left internal carotid artery was used in 33 cases (51.5\%), followed by the right ICA in 23 (35.9\%), the left vertebral artery in 7 (10.9\%), and the right vertebral artery in $1(1.5 \%)$. The right and left radial arteries were used in 52 and 12 cases, respectively (Fig 1). The left radial artery was chosen in 7 cases to catheterize a dominant left vertebral artery, in 3 cases because a right arterial line was already in place (Fig 2), and in 2 cases because the right radial artery was occluded (due to several radial coronarographies).

\section{Interventions Performed}

Thirty-four embolizations were performed using coils, 22 used a balloon-assisted coiling technique, 6 used a stent-assisted coiling technique, and 2 used a flow diverter (Table 2). Eight patients 
required $\geq 2$ TRAs: 2 for intra-arterial injection of milrinone, 2 for a second embolization, and 4 for diagnostic cerebral angiography before embolization. The mean dose-area product was $75.7 \mathrm{~Gy} \times \mathrm{cm}^{2}$, which is equivalent to the mean value obtained

Table 1: Demographic and baseline clinical characteristics of the study population

\begin{tabular}{|c|c|c|}
\hline & $\begin{array}{c}\text { Ruptured } \\
(n=33)\end{array}$ & $\begin{array}{l}\text { Unruptured } \\
\quad(n=29)\end{array}$ \\
\hline Age (mean) (range) (yr) & $52.6(31-79)$ & $54.5(37-77)$ \\
\hline Female & 16 & 16 \\
\hline BMI (mean) & 27.4 & 27.5 \\
\hline Arterial hypertension & $17(51.5 \%)$ & $18(62 \%)$ \\
\hline Current smoking & $22(66.6 \%)$ & $17(58.6 \%)$ \\
\hline Diabetes mellitus & $2(6 \%)$ & $3(10.3 \%)$ \\
\hline Alcohol abuse & $6(18.1 \%)$ & $2(6.8 \%)$ \\
\hline Dyslipidemia & $5(15.5 \%)$ & $9(31 \%)$ \\
\hline Family history of aneurysm & $2(6 \%)$ & $2(6.8 \%)$ \\
\hline Antithrombotic medications & $2(6 \%)$ & $12(41.3 \%)$ \\
\hline \multicolumn{3}{|l|}{ WFNS score } \\
\hline I & $13(39.3 \%)$ & \\
\hline II & $10(30.3 \%)$ & \\
\hline III & $1(3 \%)$ & \\
\hline IV & $3(9 \%)$ & \\
\hline V & 6 (18.1\%) & \\
\hline \multicolumn{3}{|l|}{ Fisher scale } \\
\hline 1 & $1(3 \%)$ & \\
\hline 2 & $2(6 \%)$ & \\
\hline 3 & $13(39.3 \%)$ & \\
\hline 4 & 16 (48.4\%) & \\
\hline Hydrocephalus & $10(30.3 \%)$ & \\
\hline \multicolumn{3}{|l|}{ Aneurysm site } \\
\hline AcomA & $17(51.5 \%)$ & $13(44.8 \%)$ \\
\hline PcomA & $2(6 \%)$ & $4(13.7 \%)$ \\
\hline Paraclinoid & $2(6 \%)$ & $3(10.3 \%)$ \\
\hline PICA & $1(3 \%)$ & $1(3.4 \%)$ \\
\hline Tip of the basilar artery & $1(3 \%)$ & $5(17.2 \%)$ \\
\hline $\begin{array}{l}\text { Terminus of the carotid } \\
\text { artery }\end{array}$ & $0(0 \%)$ & $1(3.4 \%)$ \\
\hline Pericallosal artery & $2(6 \%)$ & $0(0 \%)$ \\
\hline $\begin{array}{l}\text { Middle cerebral artery } \\
\text { bifurcation }\end{array}$ & $8(24.2 \%)$ & $2(6.8 \%)$ \\
\hline $\begin{array}{l}\text { Aneurysm length (mean) } \\
\text { (range) (mm) }\end{array}$ & $7(2.5-12)$ & $7.4(4-28)$ \\
\hline
\end{tabular}

Note:-BMI indicates body mass index; WFNS, World Federation of Neurologic Societies; AcomA, anterior communicating artery; PcomA, posterior communicating artery.
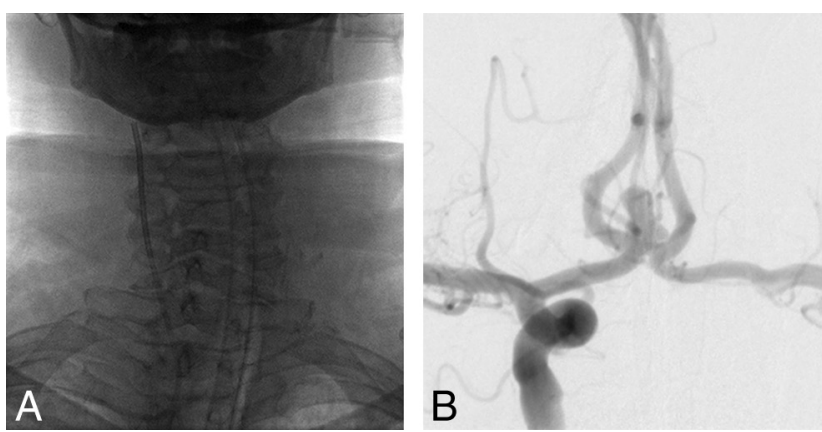

with TFA in our center during the previous year $(75.6 \mathrm{~Gy} \times$ $\mathrm{cm}^{2}$ ).

\section{Feasibility}

Two (3.1\%) attempted TRA procedures required crossover to TFA. The reasons for failure included the detection of a right axillary artery occlusion during the procedure and an acute angle between the origin of the left common carotid artery and the left subclavian artery. In the latter patient, left radial access was used because a right artery line had been placed by the anesthesiologist.

For 9 patients, TRA was not initially attempted during the embolization procedure: One of these patients did not show a pulse after 2 minutes of radial artery compression (Barbeau type D), 1 patient had a right dialysis fistula, and 2 patients had right arterial lines placed by the anesthesiologist after several attempts to puncture the left radial artery had failed. Femoral access was also used for flow-diverter placement in 3 subjects. In 2 cases, this was due to a small radial artery (diameter, $<2.5 \mathrm{~mm}$ ). In the other case, this was due to the discovery of an aberrant origin of the right subclavian artery (arteria lusoria) during diagnostic cerebral angiography with radial access a few months before embolization. Last, femoral access was chosen in 2 other cases because of the occurrence of a radial artery spasm during diagnostic cerebral angiography with a $4 \mathrm{~F}$ sheath performed a few months before embolization.

\section{Safety}

No cases of radial artery occlusion, hand ischemia, or other sequelae were observed at the puncture site. In 1 patient, however, persistent arterial bleeding at the puncture site was observed whenever the TR Band compression device was deflated (Terumo, Tokyo, Japan); hence, the device was left partially inflated for 24 hours. No radial artery occlusion was noted during follow-up. With regard to intraoperative complications, 4 patients developed coil-induced thrombi requiring an intra-arterial tirofiban injection. There were no neurologic sequelae after resolution of the thrombi. In 1 case, an aneurysm ruptured in a patient referred for embolization of a ruptured anterior communicating artery, but it did not have a clinical effect.

Five of the 33 patients with a ruptured aneurysm died (World Federation of Neurologic Societies score, 5) a few days or weeks
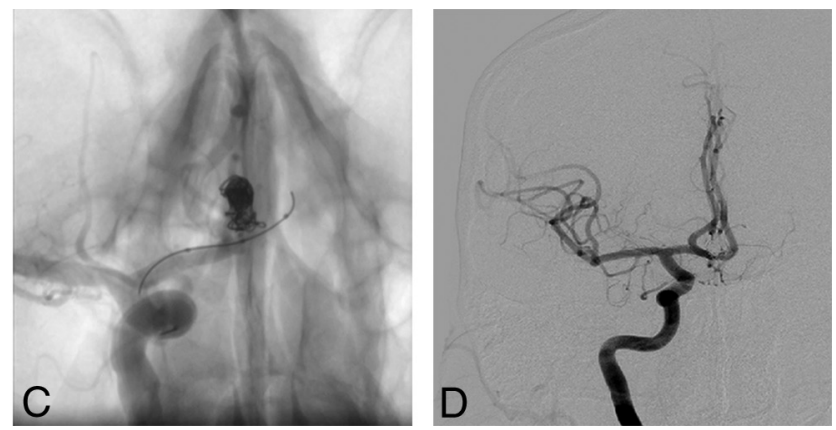

FIG 1. A middle-aged patient presenting with a ruptured bilobed aneurysm of the anterior communicating artery (measuring $6.8 \times 4.8 \mathrm{~mm}$ ), treated using balloon-assisted coiling via TRA. $A$, The right ICA was catheterized with a guide catheter via right TRA. $B$, An angiogram of the right ICA highlights the anterior communicating artery aneurysm. $C$, An angiogram of the right ICA, with a dual-lumen balloon and microcatheter in place. $D$, An angiogram of the right ICA shows the total occlusion of the aneurysm. 

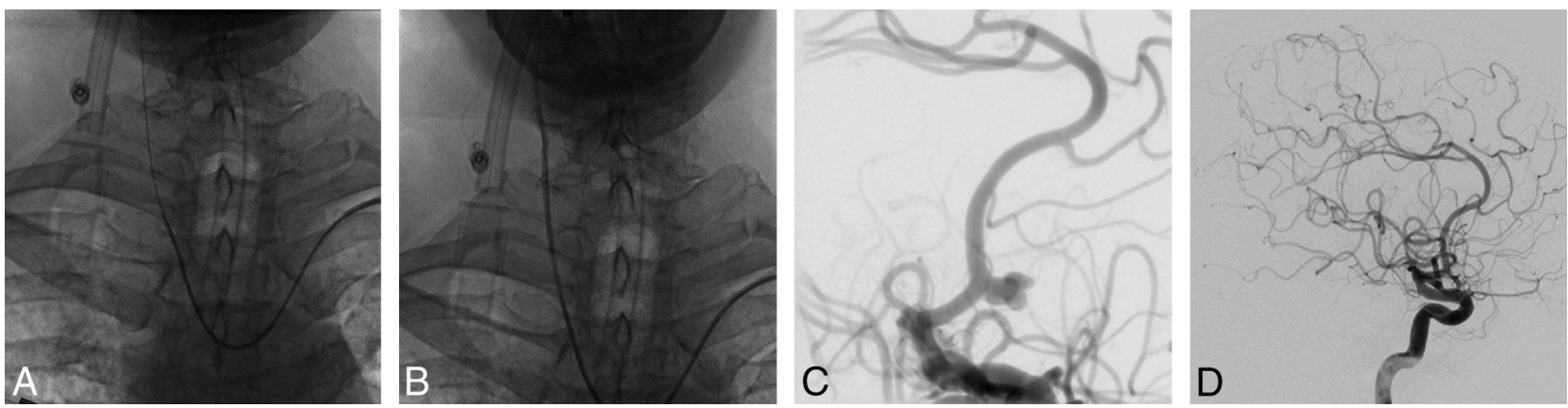

FIG 2. A middle-aged patient presenting with a ruptured aneurysm of the anterior communicating artery (measuring $7 \times 4 \mathrm{~mm}$ ), treated using coiling via left TRA. $A$, The right common carotid artery was catheterized using a Simmons shaped catheter via left TRA; then, a guiding catheter (B) was advanced over it. C, An angiogram of the right ICA highlights the irregular aneurysm of the anterior communicating artery. $D$, An angiogram of the right ICA shows the total occlusion of the aneurysm.

Table 2: Characteristics of the procedures

\begin{tabular}{lcc}
\hline & Ruptured $(\boldsymbol{n}=33)$ & Unruptured $(\boldsymbol{n}=31)$ \\
\hline TRA side & $26(78.7 \%)$ & $26(83.8 \%)$ \\
$\quad$ Right & $7(21.2 \%)$ & $5(16.1 \%)$ \\
Left & $16(48.4 \%)$ & $15(48.4 \%)$ \\
Aneurysm side & $17(51.5 \%)$ & $16(51.6 \%)$ \\
$\quad$ Right & $2(3.1 \%)$ & $0(0 \%)$ \\
Left & & \\
$\quad$ Crossover & $21(63.6 \%)$ & $13(41.9 \%)$ \\
Embolization technique & $12(36.4 \%)$ & $10(32.2 \%)$ \\
Coiling & $0(0 \%)$ & $6(19.3 \%)$ \\
Balloon-assisted technique & $0(0 \%)$ & $2(6.4 \%)$ \\
Stent-assisted technique & $2(6 \%)$ & $2(6.4 \%)$ \\
$\quad$ Flow diverter & $1(3 \%)$ & $0(0 \%)$ \\
Intraoperative thromboembolic & & \\
$\quad$ complications & &
\end{tabular}

after the embolization procedure due to progression of the initial hemorrhage. Eight patients (including 2 patients with TRA) received an intra-arterial milrinone injection for cerebral vasospasm. One patient underwent 3 TRA procedures for intracranial milrinone injection. On POD 30, three patients had an mRS score of 3 and 25 patients had an mRS score of $<2$. In all embolized patients with an unruptured aneurysm $(n=29)$, the $\mathrm{mRS}$ was the same at discharge and on POD 30.

\section{DISCUSSION}

A large number of comparative, randomized trials in the field of cardiology have shown that morbidity and mortality rates are significantly lower for TRA than for TFA. ${ }^{1-7}$ Recently, several groups have transitioned from TFA to TRA for diagnostic cerebral angiography, with good surgical results and a patient preference for radial access. ${ }^{12}$ Despite these encouraging results, most neurointerventionists consider TRA appropriate only for interventions within the posterior circulation and in cases of TFA failure. However, the safety profile of TRA is a strong argument for the transition because heparin is administered during all neurointervention procedures, and stent-assisted coiling or flow-diverter procedures requiring dual-antiplatelet therapy are increasingly frequent.
Some case reports and cohort studies ${ }^{12,14-16}$ have demonstrated the feasibility of transradial cerebral aneurysm embolization in selected cases, rather than for consecutive patients. Goland et $\mathrm{al}^{16}$ reported 40 complication-free cerebral aneurysm embolizations with right TRA. Thirty-three aneurysms were ruptured and 7 were unruptured, 35 were treated with coils, and 5 were treated with a flow diverter. Snelling et $\mathrm{al}^{14}$ reported 33 cases of TRA for unruptured aneurysm embolizations (performed with balloon-assisted coiling in 3 cases, coiling in 12 cases, a flow diverter in 11 cases, stentassisted coiling in 6 cases, and vessel sacrifice in 1 case). There were 5 crossovers: 2 due to radial artery spasms, 2 due to tortuosity of the left common carotid artery, and 1 due to tortuosity of the subclavian artery. With regard to neurologic complications, 1 patient developed an in-stent thrombus postoperatively; this was treated with intra-arterial thrombolysis with no permanent sequelae.

Neither Goland et $\mathrm{al}^{16}$ nor Snelling et $\mathrm{al}^{14}$ (Table 3) reported symptomatic radial artery occlusions, though the frequency of asymptomatic radial artery occlusion-a very important factor in complete transitions to TRA-was not specified. Indeed, the patency of the radial artery is crucial for follow-up or further embolization. At POD 30, we did not observe any radial artery occlusion, even in the 8 patients having undergone $\geq 2$ TRA procedures. In the cardiology literature, the estimated frequency of radial artery occlusion is $5 \% .{ }^{17}$ This complication is caused by the absence of intraoperative unfractionated heparin, a procedure lasting for 3 hours, a radial inner diameter/ sheath outer diameter ratio of $<1.0$, and the use of conventional hemostasis techniques rather than patent hemostasis techniques. $^{17-20}$

Furthermore, the complication rates observed during our transition phase did not differ from those reported in the literature. With regard to thrombus formation, we observed 2 cases in the ruptured aneurysm group and 2 cases in the unruptured group. All 4 were resolved by tirofiban treatment, and there were no subsequent neurologic symptoms. In the literature on TFA, the rates of thromboembolic complications and 


\begin{tabular}{|c|c|c|c|c|}
\hline & Snelling et $\mathrm{al}^{14}$ & Chen et $\mathrm{al}^{15}$ & Goland et $\mathrm{al}^{16}$ & Chivot et al \\
\hline$n$ & 33 & 49 & 40 & 64 \\
\hline \multicolumn{5}{|l|}{ Type of treatment } \\
\hline Flow diverter & 11 & 49 & 5 & 2 \\
\hline Coils & 12 & 0 & 35 & 34 \\
\hline Balloon-assisted coiling & 3 & 0 & 0 & 22 \\
\hline Stent-assisted coiling & 6 & 0 & 0 & 6 \\
\hline Vessel sacrifice & 1 & 0 & 0 & 0 \\
\hline Permanent neurologic complications & 0 & 0 & 0 & 0 \\
\hline Crossover & $15.1 \%(5 / 33)$ & $20.40 \%(10 / 49)$ & 0 & $3.1 \%(2 / 64)$ \\
\hline \multicolumn{5}{|l|}{ Failure reasons } \\
\hline Radial artery spasm & 2 & 2 & 0 & 0 \\
\hline LICA tortuosity & 0 & 4 & 0 & 0 \\
\hline LCCA origin angle & 2 & 4 & 0 & 1 \\
\hline Subclavian tortuosity & 1 & 0 & 0 & 0 \\
\hline Subclavian occlusion & 0 & 0 & 0 & 1 \\
\hline
\end{tabular}

Note:-LICA indicates left internal carotid artery; LCCA, left common carotid artery.

intraoperative rupture associated with coiling for unruptured aneurysms were $7.3 \%$ and $2.0 \%$, respectively. ${ }^{21}$ For ruptured aneurysms, the rates of thromboembolic complications and intraoperative rupture were higher: $13.3 \%$ and $3.7 \%$, respectively. ${ }^{21}$

Nonetheless, the transition to TRA requires some adjustments. First, the anesthesia team must be asked not to touch the right radial wrist for patients admitted for ruptured aneurysm. Right TRA is more suitable for cerebral embolization when the aneurysm is located on the left because the angle between the left subclavian and left common arteries is often more acute than the angle between the innominate and left arteries. At the start of our transition, we did not use the left radial artery. However, after having gained experience, we are comfortable using the left radial artery, primarily if the aneurysm is located on the right side. The left side is also very useful for posterior circulation aneurysms because the left radial artery allows direct access to the oftendominant left vertebral artery. The drawback associated with conventional left-sided access is the arm position when working on the right side of the patient. Indeed, during conventional radial access, it is difficult to maintain the arm in the supine position on the abdomen during general anesthesia because the limb tends to rotate downward. Fortunately, this problem can be solved by dorsal radial (snuffbox) access because the hand then rests in its natural position, with the palm facing the hip. The second adjustment consists of asking the intensive care team to reduce potential trauma by limiting the number of right radial artery punctures for blood gas analysis and preferring the left side.

At present, the flow-diverter procedure is the main challenge in TRA for cerebral embolization. Given the stiffness of the flow diverter, an additional proximal support is required for deployment, and a long sheath with an intermediate catheter is often essential. The long sheaths typically used in neuroradiology (such as the Neuron Max, Penumbra; and the Axs Infinity, Stryker) have an outer diameter of $2.7 \mathrm{~mm}$, which limits their use for TRA. Furthermore, the diameter of the radial artery appears to vary significantly with sex, body mass index, and ethnicity. ${ }^{22}$ Velasco et $\mathrm{al}^{23}$ evaluated the right radial artery in 100 young adult volunteers from Texas (40 men, 60 women; mean age, 35 years; mean body mass index, $27 \mathrm{~kg} / \mathrm{m}^{2}$ ). These researchers reported that the mean vessel diameter was $2.22 \pm 0.35 \mathrm{~mm}$, which is smaller than the measurements reported in populations in China $(2.38 \pm 0.56 \mathrm{~mm}),{ }^{24}$ Singapore $(2.45 \pm 0.45 \mathrm{~mm}),{ }^{25}$ and South Korea $(2.60 \pm 0.41 \mathrm{~mm}) .{ }^{26}$ Velasco et al also found that $42 \%$ of patients had an arterial diameter greater than that of a $5 \mathrm{~F}$ arterial sheath $(2.28 \mathrm{~mm}), 20 \%$ had a diameter greater than that of a $6 \mathrm{~F}$ sheath $(2.62 \mathrm{~mm})$, and only $5 \%$ had a radial artery diameter greater than that of a $7 \mathrm{~F}$ sheath $(2.95 \mathrm{~mm})$. Saito et $\mathrm{al}^{27}$ noted that the radial artery was large enough for a $6 \mathrm{~F}$ sheath in only $72.6 \%$ of female Asian patients and $85.7 \%$ of male Asian patients. The researchers also observed that for a $7 \mathrm{~F}$ sheath, the radial inner diameter/sheath outer diameter ratio was $>1$ for $71.5 \%$ of male patients and $40.3 \%$ of female patients. For an $8 \mathrm{~F}$ sheath, these proportions were, respectively, $44.9 \%$ and $24.0 \%$. Last, a ratio of $<1$ was associated with an increased frequency of radial artery occlusion. Considering the female predominance in cerebral aneurysm populations and the smaller radial artery diameter observed in Western populations and females, the 088 Triaxial system would probably not be the preferred system for flow diverter procedures.

Indeed, Chen et $\mathrm{al}^{15}$ reported that a transradial flow-diverter procedure was feasible in the absence of an 088 Triaxial system. In 15 of 49 cases (31\%), the researchers used a quadriaxial 071 - or 072 -inch system (with 5 failures, 33.3\%), and in 9 cases (18\%), they used a biaxial intermediate catheter without a guiding catheter or sheath. The 088 Triaxial system was used in only 15 of the 49 cases (31\%), and there were 3 failures (20\%). The crossover rate in the study of Chen et al was $20.4 \%$; the crossovers were prompted by an acute left common carotid artery angle in 4 patients, tortuosity of the left common carotid artery and the ICA in 5 patients, and a severe radial artery spasm in 2 patients. The crossover rate for the flow-diverter procedure currently reported in the literature is too high to generalize TRA for this purpose, but we think that for selective cases, a flow diverter is an option with a low rate of crossover. In our opinion, TRA can be the first-choice technique if we need to set up a flow diverter in the posterior circulation or at the level of the left carotid artery in case of a bovine arch configuration. For all other cases, the choice will depend on the difficulties encountered during the TRA diagnostic angiography. 
Indeed, a few weeks before the flow-diverter procedure, we systematically check the radial artery diameter to determine which device to use and we perform a TRA diagnostic angiography to assess the operational feasibility.

In our series, we selected patients according their radial artery diameter and now prefer the 088 Triaxial System. We believe that failure rates for flow-diverter procedures will decrease with the introduction of softer, more easily navigable stents, along with radial-specific access systems.

Other potential drawbacks of TRA are related to the catheter length and the degree of radiation exposure. An insufficiently long catheter may be a real issue in very tall patients, patients with tortuosities, and cases of distal TRA where the puncture site is located 3 or $4 \mathrm{~cm}$ below the usual puncture site. Fortunately, the use of a $125-\mathrm{cm}$ intermediate catheter and a microcatheter (such as the $167-\mathrm{cm}$ Headway Duo; MicroVention) may solve this issue. ${ }^{28}$ According to the cardiology literature, TRA is associated with greater radiation exposure (relative to TFA) in both diagnostic and interventional coronarography, though the difference falls with time and practice. $^{29,30}$ In the present series, the mean dose-area product was below the reference level ${ }^{31}$ and was equivalent to the dose recorded using TFA in the preceding years. To minimize operator radiation exposure, one must position the right arm alongside the right leg (rather than abducted from the leg) so that the upper shield can be placed in the position used for TFA. ${ }^{32}$

\section{Limitations}

Our study had several limitations, most of which were related to the retrospective design and the small sample size. This was a single-center study with 1 operator. Therefore, potential major differences in operator training might mean that it is not be possible to generalize our results to other catheterization centers. However, the operator here had limited prior experience in TRA (31 diagnostic cerebral angiographies), and the complication rate during the transition phase was low. Accordingly (and as reported in the cardiology literature ${ }^{33}$ ), we consider that a learning curve with 30 diagnostic cerebral angiography procedures is required to become familiar with radial access and the associated difficulties before cerebral embolization can be safely performed.

\section{CONCLUSIONS}

Our results showed that a transition to TRA for cerebral aneurysm embolization is feasible and does not increase the level of risk associated with the procedure. We were able to treat $87.3 \%$ of our patients via the TRA, with an acceptable overall rate of adverse events and a low rate of complications related to the access.

\section{REFERENCES}

1. Mamas MA, Tosh J, Hulme W, et al. Health economic analysis of access site practice in England during changes in practice: insights from the British Cardiovascular Interventional Society. Circ Cardiovasc Qual Outcomes 2018;11:e004482 CrossRef Medline

2. Jolly SS, Yusuf S, Cairns J, et al. Radial versus femoral access for coronary angiography and intervention in patients with acute coronary syndromes (RIVAL): a randomised, parallel group, multicentre trial. Lancet 2011;377:1409-20 CrossRef Medline

3. Alnasser SM, Bagai A, Jolly SS, et al. Transradial approach for coronary angiography and intervention in the elderly: a meta-analysis of 777,841 patients. Int J Cardiol 2017;228:45-51 CrossRef Medline

4. Chase AJ, Fretz EB, Warburton WP, et al. Association of the arterial access site at angioplasty with transfusion and mortality: the M.O. R.T.A.L study (Mortality benefit Of Reduced Transfusion after percutaneous coronary intervention via the Arm or Leg). Heart 2008;94:1019-25 CrossRef

5. Valgimigli M, Gagnor A, Calabró P, et al; MATRIX Investigators. Radial versus femoral access in patients with acute coronary syndromes undergoing invasive management: a randomised multicentre trial. Lancet 2015;385:2465-76 CrossRef Medline

6. Brueck M, Bandorski D, Kramer W, et al. A randomized comparison of transradial versus transfemoral approach for coronary angiography and angioplasty. JACC Cardiovasc Interv 2009;2:1047-54 CrossRef Medline

7. Wang YB, Fu XH, Wang XC, et al. Randomized comparison of radial versus femoral approach for patients with STEMI undergoing early PCI following intravenous thrombolysis. J Invasive Cardiol 2012;24:412-16 Medline

8. Kok MM, Weernink MG, von Birgelen C, et al. Patient preference for radial versus femoral vascular access for elective coronary procedures: the PREVAS study. Catheter Cardiovasc Interv 2018;91:1724 CrossRef Medline

9. Neumann FJ, Sousa-Uva M, Ahlsson A, et al. 2018 ESC/EACTS guidelines on myocardial revascularization. Eur Heart J 2019; 40:87-165 CrossRef Medline

10. Ball WT, Sharieff W, Jolly SS, et al. Characterization of operator learning curve for transradial coronary interventions. Circ Cardiovasc Interv 2011;4:336-41 CrossRef Medline

11. Benamer H, Louvard Y, Sanmartin M, et al. A multicentre comparison of transradial and transfemoral approaches for coronary angiography and PTCA in obese patients: the TROP registry. EuroIntervention 2007;3:327-32 CrossRef Medline

12. Snelling BM, Sur S, Shah SS, et al. Transradial cerebral angiography: techniques and outcomes. J Neurointerv Surg 2018;10:874-81 CrossRef Medline

13. Brunet MC, Chen SH, Sur S, et al. Distal transradial access in the anatomical snuffbox for diagnostic cerebral angiography. $J$ Neurointerv Surg 2019;11:710-13 CrossRef Medline

14. Snelling BM, Sur S, Shah SS, et al. Transradial approach for complex anterior and posterior circulation interventions: technical nuances and feasibility of using current devices. Oper Neurosurg (Hagerstown) 2019;17:293-302 CrossRef Medline

15. Chen SH, Snelling BM, Shah SS, et al. Transradial approach for flow diversion treatment of cerebral aneurysms: a multicenter study. $J$ Neurointerv Surg 2019;11:796-800 CrossRef Medline

16. Goland J, Doroszuk GF, Garbugino SL, et al. Transradial approach to treating endovascular cerebral aneurysms: case series and technical note. Surg Neurol Int 2017;8:73 CrossRef

17. Feldman DN, Swaminathan RV, Kaltenbach LA, et al. Adoption of radial access and comparison of outcomes to femoral access in percutaneous coronary intervention: an updated report from the national cardiovascular data registry (2007-2012). Circulation 2013;127:2295-306 CrossRef Medline

18. Aykan AÇ, Gökdeniz T, Gül I, et al. Comparison of low dose versus standard dose heparin for radial approach in elective coronary angiography? Int J Cardiol 2015;187:389-92 CrossRef Medline

19. Pancholy SB. Comparison of the effect of intra-arterial versus intravenous heparin on radial artery occlusion after transradial catheterization. Am J Cardiol 2009;104:1083-85 CrossRef Medline

20. Pancholy S, Coppola J, Patel T, et al. Prevention of radial artery occlusion-patent hemostasis evaluation trial (PROPHET study): a randomized comparison of traditional versus patency documented hemostasis after transradial catheterization. Catheter Cardiovasc Intervent 2008;72:335-40 CrossRef Medline 
21. Pierot L, Wakhloo AK. Endovascular treatment of intracranial aneurysms: current status. Stroke 2013;44:2046-54 CrossRef Medline

22. Peruga JP, Peruga JZ, Kasprzak JD, et al. Ultrasound evaluation of forearm arteries in patients undergoing percutaneous coronary intervention via radial artery access: results of one-year follow-up. Kardiol Pol 2015;73:502-10 CrossRef Medline

23. Velasco A, Ono C, Nugent K, et al. Ultrasonic evaluation of the radial artery diameter in a local population from Texas. I Invasive Cardiol 2012;24:339-41 Medline

24. Nie B, Zhou YJ, Yang Q, et al. Safety and feasibility of repeated percutaneous transradial coronary intervention in the same route. Chin Med J (Engl) 2012;125:221-25 Medline

25. Loh YJ, Nakao M, Tan WD, et al. Factors influencing radial artery size. Asian Cardiovasc Thorac Ann 2007;15:324-26 CrossRef Medline

26. Yan Z, Zhou Y, Zhao Y, et al. Anatomical study of forearm arteries with ultrasound for percutaneous coronary procedures. Circ J 2010;74:686-92 CrossRef Medline

27. Saito $S$, Ikei $H$, Hosokawa $G$, et al. Influence of the ratio between radial artery inner diameter and sheath outer diameter on radial artery flow after transradial coronary intervention. Catheter Cardiovasc Intervent 1999;46:173-78 CrossRef Medline
28. Gross BA, Kenmuir CL, Ares WJ, et al. Pericallosal aneurysm coiling with a "hubbed" $167 \mathrm{~cm} 0.013$ " Headway duo via a transradial approach. J Clin Neurosci 2018;53:273-75 CrossRef Medline

29. Plourde G, Pancholy SB, Nolan J, et al. Radiation exposure in relation to the arterial access site used for diagnostic coronary angiography and percutaneous coronary intervention: a systematic review and meta-analysis. Lancet 2015;386:2192-203 CrossRef Medline

30. Sciahbasi A, Frigoli E, Sarandrea A, et al. Radiation exposure and vascular access in acute coronary syndromes: the RAD-Matrix trial. J Am Coll Cardiol 2017;69:2530-37 CrossRef Medline

31. Miller DL, Kwon D, Bonavia GH. Reference levels for patient radiation doses in interventional radiology: proposed initial values for U.S. practice. Radiology 2009;253:753-64 CrossRef Medline

32. Sciahbasi A, Frigoli E, Sarandrea A, et al. Determinants of radiation dose during right transradial access: Insights from the RADMATRIX study. Am Heart J 2018;196:113-18 CrossRef Medline

33. Hess CN, Peterson ED, Neely ML, et al. The learning curve for transradial percutaneous coronary intervention among operators in the United States: a study from the National Cardiovascular Data Registry. Circulation 2014;129:2277-86 CrossRef Medline 